
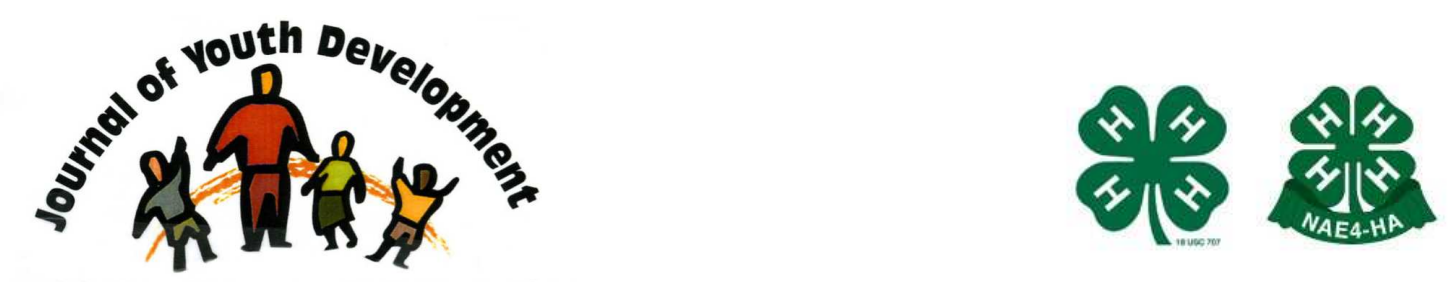

Bridging Research \& Practice

\title{
From 4-H International Youth Exchange to Global Citizen: Common Pathways of Ten Past Program Participants
}

\author{
Mary E. Arnold \\ Youth Development \\ Oregon State University \\ Corvallis, OR \\ mary.arnold@oregonstate.edu \\ Jamie Davis \\ 4-H Youth Development, Lake County \\ Oregon State University \\ Lakeview, OR \\ jamie.davis@oregonstate.edu
}

\author{
Aimee L. Corliss \\ 4-H Youth Development \\ Oregon State University \\ Corvallis, OR \\ corlisai@onid.orst.edu
}




\title{
JOURNAL OF YOUTH DEVELOPMENT \\ bridging research and practice

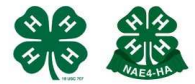

Volume 9, Number 2, Summer 2014

Article 140902RS001

\section{From 4-H International Youth Exchange to Global Citizen: Common Pathways of Ten Past Program Participants}

\author{
Mary E. Arnold, Jamie Davis and Aimee L. Corliss \\ Oregon State University
}

\begin{abstract}
This qualitative study examined the life course of ten adults who participated as youth in the 4-H International Exchange program. The purpose of this research was to explore the pathways that led each participant to their exchange experience as a youth and how that experience set the stage for further development into an adulthood marked by cultural interest, awareness, competence and global citizenship. Using a grounded theory approach the data were analyzed through selective, open, and axial codings that elucidated a series of key events, opportunities, and qualities that form a common pathway among all participants. The results of this research contribute to the articulation of a theory of change upon which international youth exchange programs can be effectively developed and enhanced. Specific recommendations for international youth exchange programs are presented.
\end{abstract}

\section{Introduction}

Critical for success in the $21^{\text {st }}$ century workforce is the knowledge and understanding of other countries, cultures, and languages (U. S. Department of Education, 2012). International exchange programs for youth have tremendous potential to contribute to this important need by providing authentic international experiences for youth that promote the development of culturally aware, global citizens. One of the persistent problems with determining the long-term impact of international youth exchange programs is the length of time between program participation and potential long-term outcomes. In many cases it may be 10, 20 or even 30 years before one can see such long-term results, and during that time youth participants have experienced many other influences and opportunities that shape who they become as adults.

Given the complex nature and daunting task of isolating specific long-term program effects, this study turned instead to examining the life course of ten adults who participated as youth in the 4-H International Exchange program. The purpose of this research was to explore the pathways 
that led each participant to their exchange experience as a youth and how that experience set the stage for further development into an adulthood marked by cultural interest, awareness, competence and global citizenship. The ultimate goal of the research was to describe a series of key events, opportunities, and qualities that in turn could articulate a theory of change upon which international youth exchange programs can be effectively developed and enhanced.

\section{Review of the Literature}

In a recent report the U. S. Department of Education (2012) outlined four key reasons for increasing global competency in youth. First, a global economy increases the competiveness of the job market, meaning today's young people will be competing for jobs with others from around the world. Consequently, the world's labor force will be more international as well, requiring workers to have cultural awareness and effective intercultural communication skills. Second, the impact of concerns that were once more localized, such as infectious disease, financial concerns, and natural disasters increasingly require global awareness, collaboration, and cultural understanding to address. Third, national security and diplomacy is increasingly dependent on global awareness and civic engagement. Fourth, the increasing diversity of the U.S. workforce requires that young people are equipped with the skills to communicate and work effectively with people from different cultural backgrounds.

Despite the long history of international exchanges, and the increasing importance of such exchanges, there is limited research on the impact of these programs. Much of the research that has been done is also becoming dated in light of fast-paced globalization. The studies that have been conducted, however, are consistent in their findings that youth participation in international exchange programs contributes to the development of an international sensibility. For example, Hansel (1988) found that international exchange programs resulted in students developing a better appreciation of foreign culture; increased ability in a foreign language; increased critical thinking; and lessened materialism. Similarly, Boyd, et al. (2001) found that youth participants in the 4- $\mathrm{H}$ international youth exchange perceived they were more sensitive to other cultures and more aware of global events. Bachner, Zeutschel, \& Shannon (1993) also found evidence that participation in an international exchange leads to a greater global perspective and cultural competence, noting that participants often cited instances where they reported influencing a person or situation because of what they had learned on the exchange. Even more recently, Olberding and Olberding (2010), in a study focused on youth peacebuilding and exchange programs found that exchange programs have the ability to enhance direct participants' global competency, and in many cases there is also an indirect ripple effect in learning beyond the participants themselves to the chaperones, host families, other students and teachers.

The research cited above is limited in methodological approach to retrospective self-report questionnaires, with limited investigation into the processes of the exchange itself. Bachner, Zeutschel, and Shannon (1993) point out the complexities of studying the effects of youth exchange, and suggest the appropriateness of qualitative investigations, specifically those using a "life story" approach, for understanding the impact of international exchange programs. Indeed, in a second phase to their study Bachner, Zeutschel, and Shannon (1993) conducted follow-up interviews to understand the longer-term impact of participation in the exchange and found that, over the long-term, participating in the exchange enhanced the participants' international perspective and cultivated support for international peace and cooperation. 
International youth exchanges are limited in scope - generally ranging from a few weeks abroad, to up to a year in some cases. And yet, the limited research that has been conducted, seems to support a long-term impact on exchange participants. And it is this long-term impact that is needed in order to address the global citizen needs for young people as outlined by the U. S. Department of Education (2012). Given the limited timeframe of most programs and the anticipated long-term outcomes for the programs, it makes sense that there may be additional common experiences for program participants between the time they participate in an exchange as youth and becoming global citizens as adults. Using Bachner, Zeutschel, and Shannon's (1993) call for the use of life stories to understand complex phenomena, this study seeks to elucidate the life course of selected program participants from the time of participation in a 4-H international exchange program, and their adult life that is marked by many of the outcomes articulated as important for a thriving global world.

\section{Methods}

Qualitative research is inductive in nature; a process that focuses on the emergence of a phenomenon, often times in a natural setting, rather than a carefully controlled research environment. In its purest sense, qualitative inquiry assumes no a priori knowledge of what is being studied, although this purity is rarely achieved as the researcher always brings his or her own understanding, assumptions, and ideas about what is being studied to the process. As such, qualitative research is at its core interpretive, as the goal is for the researcher to interpret and make sense of the data (Creswell, 2003). The goal of qualitative research is to let the data tell its own story so that the phenomena being studied can be better understood.

There are several well-known approaches to qualitative research, each with its own goals and strategies. The approach used in this study best fits with the grounded theory approach (Strauss, \& Corbin, 1990), a process by which the researcher attempts to derive a theory from the experiences of research participants (Creswell, 2003). In this case, we were interested in trying to uncover a pathway or series of common experiences that take a young person from participating in a $4-\mathrm{H}$ international exchange program as an adolescent to an adult life that is marked by continued international/global interest and involvement. Through this research we hoped to uncover the key program elements and post-program opportunities that are critical steps along the pathway, with the ultimate goal of developing a theory of change (Anderson, 2005) that can predict the long-term impact of youth international exchange programs, which is to produce global citizens.

Grounded theory analysis relies on a series of three different codings of text, in this case the transcripts of the interviews that were conducted with past program participants:

1. Selective coding- is the process of choosing one or more categories to be the core categories around which the story is developed (Strauss, \& Corbin, 1990). In this study we believed that there are core life course experiences that participants likely encountered and the interview protocol was built around those experiences, for example how the person learned about the exchange opportunity, the exchange experience itself, post-exchange travel, college major and opportunities, and career choices.

2. Open coding-is the process of identifying, naming, categorizing, and describing the phenomena found in the text, and organizing the open codes around the selective codes. In the open coding portion of the analysis we looked specifically for those common experiences under each of the selective codes that provided further elucidation. For example, we learned that important common themes under the selective code of "exchange experience" were the quality of the host family relationships, the authentic 
cultural experiences the host family provided, and the impact of the exchange on the youth's personal development.

3. Axial coding- which is the final step in the analysis is the process of connecting the open codes together to tell a story. In this study, the goal of the axial coding was to reveal an "ultimate pathway" that described the key process of events and opportunities that need to take place in order for a one to move from a young person participating in an international exchange program to a global citizen as an adult.

\section{Participants}

Participants for this study were purposefully selected. The purposeful selection of research subjects is a common technique in qualitative research. The goal of this type of selection is to find participants who will best help the researcher understand the phenomena being studied (Creswell, 2003). Participants were recruited through an e-mail to state 4-H international program coordinators who were asked to identify past international exchange participants who had pursued international careers or interests, and whom they thought could articulate the connections between their experience as an exchange youth and where they are now in their lives.

\section{Participant Screening Interview}

At total of 23 individuals were nominated by state coordinators. The research team was able to make e-mail contact with 20 , of which thirteen returned an e-mailed screening questionnaire. The screening questions related to the person's basic experience, current situation, and ability to share experiences about the exchange and subsequent life events in detail. Following the screening, ten participants were selected to be interviewed, which was the target number for the study. Each participant was sent an informed consent document and asked to read, sign, and return it to the researcher. Once the informed consent was received participants were contacted to arrange a time for the interview to take place.

The participants were diverse, and reflected a broad range of age and experience. The youngest participant was 19; the oldest was 53, with a median age of 33.

All interviews were conducted by the same member of the research team, which allowed for consistency across interviews. The interviews were conducted over the phone using a private Adobe Connect website, to which the audio from the phone line was connected. This allowed the interviewer to record the interviews directly from the phone conversation. Once the interview was concluded, the interview was downloaded and transcribed verbatim by another member of the research staff. Once the transcripts were checked for accuracy and de-identified, the recordings were deleted from the Adobe Connect site.

\section{Instrument}

The interviews followed a semi-structured interview protocol that was developed by members of the research team. The interview was based on the series of events/stages that one might expect a young person to go through from the time of an international youth exchange to establishing a career. These stages formed the selective coding for the study and included: 1) Youth experience before going on the exchange; 2) experience on the exchange; 3) the immediate impact of the exchange; 4) college; and 5) career. The questions themselves were developed based on the (somewhat limited) research that has been conducted on youth exchange programs. 
The draft protocol was shared with three outside 4-H professionals with considerable experience in 4- $\mathrm{H}$ international programs and modified based on their helpful feedback. The final version of the protocol was reworked with the person conducting the interviews to match the language and flow of the questions to her personal interviewing style.

\section{Data Analysis}

Transcriptions of all 10 interviews were printed out for each member of the research staff $(n=3)$ to read completely. Transcripts were then uploaded into MAXQDA, for coding by two members of the research staff. In addition, coding was conducted by hand on the hard transcripts with the lead researcher and another member of the research staff. The goal of the multiple coding processes was to triangulate the results among research staff to ensure completeness and accuracy (Flick, 2007). Once the coding process was complete, the selective and subsequent open codes were written on a large white board with key examples of each code from multiple interviews listed beneath. Key axial codes were developed based on the relationships indentified among the selective and open codes.

\section{Results}

The results of the research revealed considerable consistency in experience across all ten participants, both in terms of experiences in the selective coding areas that represent the predictable life course patterns, and also within the open coding areas that emerged during the analysis process.

\section{Pre-Exchange Experience}

Three main themes emerged across the interviewees regarding their experience before going on the exchange: 1 ) Experience in 4- $\mathrm{H}$ and learning about the exchange opportunity; 2 ) the role of the family in encouraging and supporting an exchange; and 3) the opportunity to host youth from another country prior to going on an exchange themselves.

\section{4-H Experience}

All the participants talked about their experience in $4-\mathrm{H}$, with most having considerable longterm 4-H membership. It was through interactions with 4-H that participants learned about the international program and began to think that it might be an opportunity for them, and one of the main ways they learned about the program was through hosting an international youth first. Others talked about an "ah-ha" moment when listening to another youth who shared their experience about going on an exchange. In more than one instance there was an immediate nascent awareness that an exchange might be something he or she would like to do. Others described the role of 4- $\mathrm{H}$ staff in facilitating their interest in the exchange, such as for the following participant who made a quick decision to go, but was supported with detailed information about the options that were available, and helped to choose the best option for her interests:

\section{Family Experience, Support, and Encouragement}

All participants had families that supported their involvement in the international exchange program. Many reported having older siblings who either hosted an international student or went on exchanges. Some shared that their parents encouraged travel, and others traveled 
abroad periodically with family for vacation or to visit family abroad. Two participants had mothers who had gone on an international exchange as a youth.

\section{Hosting an International Youth}

Seven of the ten participants reported hosting a youth from another country prior to going on an exchange; one hosted after going on the exchange. Hosting a youth from another country had profound impacts on the participants, particularly in their desire to go on an exchange themselves, and to continue hosting youth from other countries:

\section{Experience on the Exchange}

The analysis of the participants' experience while on the 4-H international exchange revealed three common themes: 1 ) The qualities of the host family; 2 ) the impact of the host family on the youth; and 3 ) the experiences that the host family provided for the participant.

\section{Host Family Qualities}

The quality of the host family played a significant role in the experience that the participants had abroad. All participants reported that their host families were warm, friendly, and welcoming. Participants felt included as members of the family and developed close relationships with their host parents and siblings. The participants reported being made to feel at ease, and were grateful for the opportunities the host family provided for them. In some cases the host families knew English, in others they did not (at least not very well) and while the language differences posed some difficulty at times, it did not prevent a deep bond from developing between the participant and their host family. In some instances, participants had the opportunity to stay with two different families which offered a richer experience for the participant.

\section{Host Family Impact}

Overwhelmingly, the participants reported that being exposed to the traditional cultures and daily life of the host family and country was the most important part of their exchange experience. For many participants this was the first time they became aware of the differences between cultures and that many things they think about and do in the United States, even simple everyday things, can be very different in other cultures:

A key impact of the experience was the participants' new awareness that they, too, had their own culture to share, which resulted in a sense of mutuality between the participants and hosts as they shared their culture with each other. This helped the participants see that they were not just on the exchange for their own benefit, but that they were there to teach the host family as well. Many participants reported returning to visit their host families later, and some hosts even came to the United States as well.

\section{Host Family Experiences}

The third theme of the participants' experience on the exchange had to do with the experiences that the host families provided. Being immersed into the culture was a key aspect of the best experiences, and the participants emphasized the importance of "not being a tourist." The immersion helped the participants to see how limited their perspective of the world had been before the exchange, and to develop a larger, more global perspective. Participants particularly enjoyed that the host family was willing to show off their culture and to involve them in the daily life, rituals, day trips, holidays and special events. The opportunity to be included at the 
family level served to connect the participant even more closely with the host family and the culture as a whole.

\section{General Impact of the Exchange}

Beyond the impact of the host family experience, three themes emerged that touched on the general impact of the exchange on participants: 1) The desire for more travel; 2) development of self-confidence; and 3) ever increasing cultural awareness.

\section{Post-Exchange Travel}

Every one of the participants continued to travel abroad following their 4-H exchange experience. Many travel experiences were connected to college opportunities (explored in more depth later in this report). Returning to the host country was a primary goal for many participants. All but one reported going back to their host country one or more times, and a few went on additional sponsored exchanges. Additionally, five participants have lived abroad for at least some time since their exchange, one on a two-year assignment with the Peace Corps in West Africa, others for extended stays teaching in Japan:

\section{Development of Self Confidence}

The development of self-confidence was something that almost every participant talked about in relationship to their exchange experience. Many spoke of the developmental impact of the program, in that they entered into the exchange (most in their teen years) with limited experience and uncertainty of how well they would manage the exchange, and emerged with new skills and self-confidence. The opportunity to be placed in a strange country, but surrounded by a supportive host family, helped the participant to see that he or she could enter into a totally unknown situation and do just fine. The boost to participants' self-confidence that came from finding out they could be successful at the exchange was one of the most common themes touched upon.

Another area of confidence development was reflected in positive risk taking. One participant shared what he learned in relationship to the language barrier, and how he risked taking the lead to improve it, and even further, how taking this risk impacted his ability to express his ideas once he had returned home. This experience also illustrates the change in awareness of self that many participants expressed, which is particularly keen in light of the natural developmental tendency of adolescents to be self-focused, as illustrated above where the participant first interpreted the reason for his host brother's silence as the host brother not liking him. Many participants touched on how their own awareness of self, especially in relationship to others was influenced by their experience on the exchange.

\section{Increasing Cultural Awareness}

Participation in the 4-H international exchange program leads to increased cultural awareness. As noted above, this awareness was greatly facilitated by the experience with the host family, often in very mundane daily encounters. Many of the participants came to their exchange with an expressed desire to learn all they could, to experience the other culture fully. One participant reported that he was not interested in the exchange at first because he or she did not want to be a tourist, and it was only after he realized the potential for cultural immersion that the exchange looked inviting.

There appears to be little question that the experience helped set a life course in motion. Participants could easily identify that their exchange experience played a pivotal point in the 
future life trajectory, although from that point the life paths take distinctly different routes. One similarity we found beyond the exchange itself was the commonality in choice of college majors, all of which had an international aspect. Another commonality is in the definitively international spirit of those participants who have entered the workforce and career.

\section{College}

Three of the participants are currently in college, all pursuing a four-year degree in an international field of study. Six of the remaining participants attended college and completed at least a four-year university degree, with only one not completing a college degree (but still working in an international career). The college majors of the participants are highly varied but all have an international component in common. Participants could make a clear connection between the exchange program and their choice of college studies; this finding is one of the most profound that we encountered in mapping the life path of the participants. In considering the role that college played or is playing for the participants, three themes emerged: 1) the choice of college major; 2) the opportunities for international experience that were present; and 3) additional travel opportunities that college provided.

\section{College Majors}

Nine participants made a clear connection between their experience on the exchange and their choice of college major, often drawing connections between an increased awareness of themselves as a result of going on the exchange and their chosen course of study. One participant described the "ah-ha" moment of connecting a passion for agriculture, travel, and helping others into major in international agri-business, and another talked about how the exchange provided an opportunity for her to engage the world far from the small rural town in which he or she grew up. An additional participant realized how her long-time love of learning about people was fanned into a major in anthropology after re-reading her journal from her exchange.

\section{Opportunities for Additional International Experiences and Travel in College} College provided additional opportunities for the participants to continue their global development beyond just their chosen course of study. Opportunities to study languages in more depth, internships, and stateside international opportunities, such as a program to befriend a visiting college exchange student, all allowed the participants to continue to explore their passion for international experiences. Several participants took advantage of study abroad programs and/or opportunities for service trips in other countries as well during their time in college.

Another participant described in great detail how the 4-H exchange experience, followed by an IFYE exchange to Finland, helped her understand how important it is to travel to and experience other places one is interested in. This understanding underscored her continual travel throughout college as well as her future plans to secure a career in anthropology and global ocean health.

\section{Career}

Our pathway analysis ends at the post-college careers of the participants, which varied widely, but all of which have a distinct international aspect. Seven of the participants are now in careers, some in their early years, some as seasoned professionals, but all articulated a direct connection between their experience on the international exchange and where they are now. For example, one participant articulated how his comprehensive understanding of Asian culture 
and language makes it possible for him to be effective in sourcing fine jewelry from Asia for his stateside shop. What began as one trip to Japan on exchange at age 18 took him on a course to multiple trips to Japan and China, living in Japan, becoming fluid in Japanese, and obtaining an advanced degree in international business- all to return home to establish a jewelry store in his home town. This participant stressed the importance of being able to communicate and work within the norms of a culture as key to his success, an understanding that he gained through prolonged international experience beyond his first exchange to Japan.

Another participant, originally from a small rural town describes "her whole life being about Japan/U.S. relations." From her 4-H exchange, to majoring in Japanese and International studies in college, to a LABO internship, to a career as a diplomat she described in detail how her passion and education has resulted in a fulfilling international career:

\section{Axial Coding: Charting the Pathway}

The final stage in the coding process involved establishing the axial codes that serve as key points for the summary and implications of this research. The purpose of axial coding is to "put the data back together" by making connections between the categories established in the open coding process (Strauss, \& Corbin, 1990 p. 96). In order to best address the purpose of the research, we were interested in considering the causal conditions and relationships between the open codes that lead to the development of global citizenship. The analysis revealed 15 key axial codes that are presented in Figure 1.1, and described in detail below by coding number. 


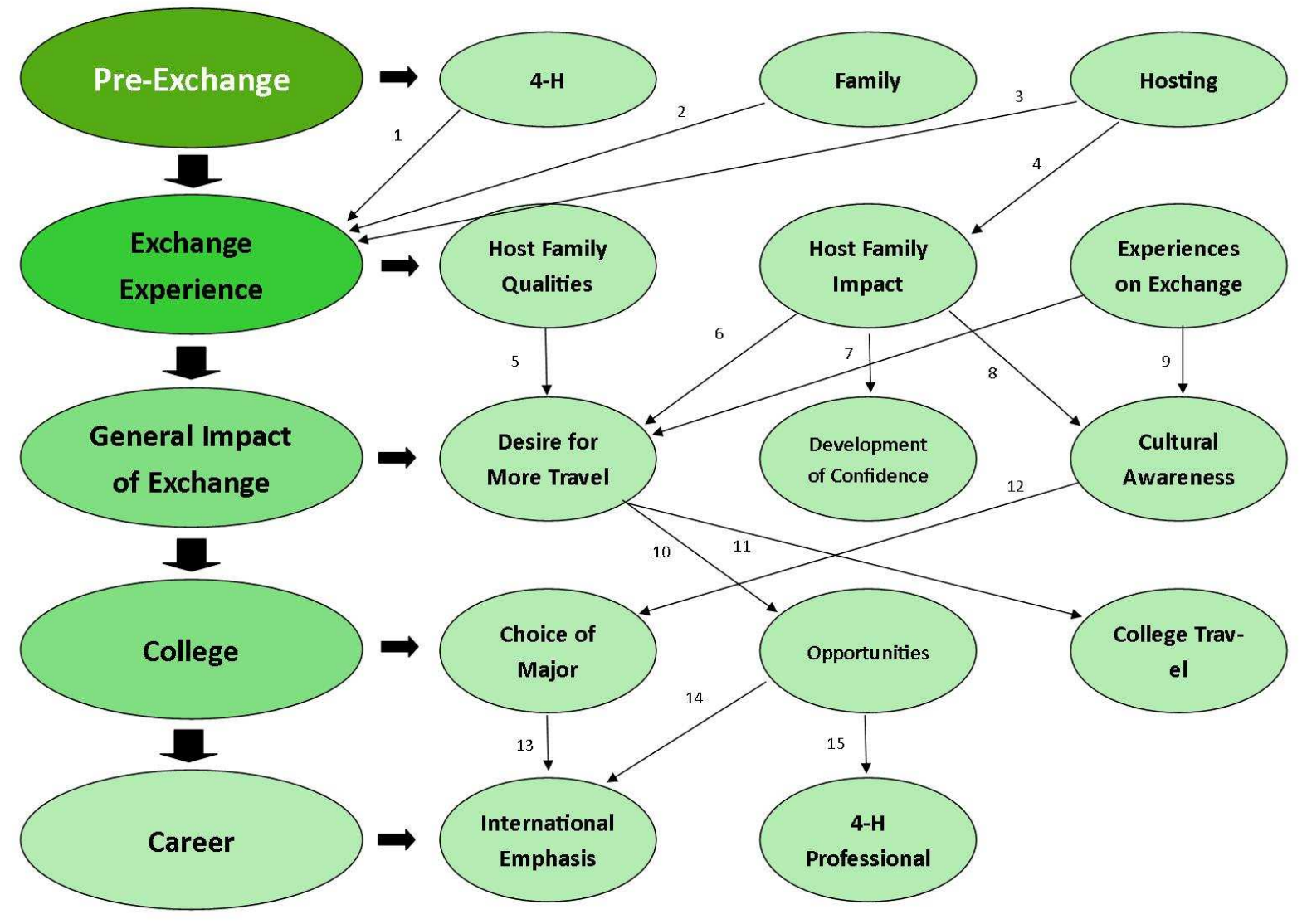

\section{Axial Code Descriptions}

1. Not surprisingly, there is a key connection between a youth's participation in 4-H and the decision to participate in a $4-\mathrm{H}$ international exchange. This relationship is enhanced through 4-H staff who promote the program and help youth navigate details and decisions related to the exchange. This connection is also enhanced by youth who share their experience on the exchange with youth once they have returned. It is particularly powerful for youth to realize that they are interested in an exchange by listening to youth who have gone before. Youth also gain confidence in the idea of traveling abroad when they witness other youth who have done so.

2. The family places a key role in setting the stage for the youth to go on an international exchange program. Many of the participants talked about their parents' encouragement of travel and the importance of having a broad perspective. Others talked about their parents' support for their desire to go on an exchange, and a few had parents who had gone on an exchange themselves. Another key factor was having older siblings who participated in an exchange. The participants in this study all came from families that valued, encouraged, and supported the youths' desire to participate in the exchange. 
3. Hosting exchange youth from other countries is an important step on the pathway to global citizenship. Many study participants spoke of the connections they made with the international youth they hosted, which often was their first moment of awareness of cultural differences. Navigating languages was one of the first points of this awareness, but understanding difference in cultures and customs and every day activities served to pique the participants' interest in exploring other cultures through an exchange.

4. The hosting experience provides an opportunity for youth to be prepared to be hosted themselves. Many reported understanding what it takes to be a good host because they had been one, which in turn led them to an awareness of the impact their own exchange on their host family. Participants reported being willing to immerse themselves in the opportunities that their host families provided, and were aware of the sacrifices the host family was making to provide them with a cultural immersion experience. Through hosting, participants were better prepared to navigate the language differences as well as cultural differences while abroad.

5. Once on the exchange the quality of the host family played an important role. There a myriad of subtle ways the host family influenced the participants, but the key connection in terms of the axial coding appears to be the way in which the host family set the stage for the youth to desire more travel. Host families that were welcoming, inclusive, supportive, entertaining, and that shared their culture through daily activities and special events provided a positive, enriching experience for the youth, and whet their appetite to explore different cultures even more. In terms of our analysis, it is clear that the experience with the host family is one of the key axial links to global citizenship. Another key aspect of the host family's impact on additional travel is the desire of the youth to return to their host country and family again.

6. --8. The impact of the host family plays one of the most critical links toward global citizenship. As mentioned above, the host family enhances the participants' desire for more travel, this, however, is intertwined with the development of confidence. High quality host families help youth to develop more confidence as they navigate a new culture and language in a supportive, fun environment. This confidence builds overtime, and translates to youth's desire to take on additional explorations and challenges, specifically through more travel experiences.

9. Another key link is between the experiences that a youth has on the exchange and the growing cultural awareness that develops as a result of opportunities provided by the host family. Participants spoke about the significant impact of simple things like cooking, marketing, and brushing one's teeth, but also about the broader cultural and traditional experiences provided by the host family that profoundly impacted their development of cultural awareness, which in turn has a significant impact on choice of college major as we will see in axial code 12 .

10.--11. All of the participants reported having the desire to travel more following their exchange. For some this took the form of family trips abroad, or other independent travel in young adulthood. Much of the post-exchange travel took place as a result of opportunities in college. One way this took place was through the opportunities that college provided for travel which were largely service or internship opportunities (Code 10), A second avenue was through more extended opportunities such as a semester abroad, or extended stays in other countries (Code 11). 
12. One of the most convincing axial connections we discovered was the relationship between the participants' growing cultural awareness and the choice of college major, which all had an international component. Of particular note is the creative way in which participants developed their own course of studies from their growing international interest; often combining multiple interests to form their course of studies.

13. For those who are in the workforce, the choice of college major had a direct connection on a career with an international emphasis. Of note is that most of these careers are stateside, with only one currently working abroad. These careers, however, are marked by continued international travel and engagement with other cultures, including trading in commodities as disparate as farm see and fine jewelry.

14. In addition to the choice of college major, the opportunities provided in college through study, internships, and travel contributed to the participants' international careers. These opportunities provide time and experiences for the participants to travel more, develop international connections, and hone language skills, all of which were valuable parts of their career development and success.

15. Finally, one connection that is likely an idiosyncratic result of our sampling, but nonetheless noteworthy, is the number of participants who are now working in 4-H. Five of the participants have or are currently working with 4-H international program, either as a career as college interns and volunteers. It is clear that 4-H program itself offers international career opportunities for participants to pursue, which takes us full circle to axial connection number one that highlights the role of the 4-H program as a key first step along the path from rural youth to global citizen.

\section{Conclusion and Implications}

The goal of this research was to explore the life pathways of 4-H international exchange program participants in order to arrive at a theory of change that is grounded in the lived experiences of the participants we studied. A theory of change defines the essential building blocks that are needed to achieve a long-term program goal (Anderson, 2005). Theories of change are valuable to program planners and stakeholders because they contribute to a common definition and vision of long-term program goals, how those goals can best be reached, and what critical program qualities need to be monitored and evaluated for successful achievement of the long term outcomes.

The results of this research revealed some key life experiences, or building blocks, that connect a person's experience in the 4-H international exchange program as a youth, and achievement of the long-term goal of the program, which is adulthood marked by international and global awareness and citizenship. The results have several implications for youth international exchange programs.

First, recruitment of youth program participants is important, specifically in terms of ensuring there is an enthusiastic spokesperson for the program. Many of the youth in the study reported learning about the program through people who presented the opportunity in a way that was personally connecting. Youth also reported their interest and excitement in sharing their experiences on the exchange, and should be invited to share their experiences through meaningful and thoughtfully arranged forums. Recruitment should focus on the authentic 
opportunities for learning and development abroad, the impact of the program on youth (e.g. building confidence; learning about new cultures), the opportunities that past program participants have had as a result of the exchange, and emphasize the experience as one that could not be gained through a visit as a tourist.

Second, youth and their families should be encouraged to host youth from other countries, ideally prior to going on their own international exchange. As we learned from the participants in this study, hosting a youth from another country can be a way to practice negotiating language and cultural differences while still at home. Hosting an international youth can be a catalyst for a young person's desire to travel and learn about other countries and cultures. Hosting can also prepare a youth to be hosted while abroad, by increasing awareness of the investment the host family makes in hosting and the effort that is necessary from the hosted youth for the experience to be successful for both parties.

Third, the quality of the host family matters. This study clearly revealed the vital role that the host family plays in the exchange. While at least some common language ability is helpful, language differences do not seem to pose too much problem. However, it is critical that the family be welcoming and warm, and that they are willing to provide an authentic experience for the youth they are hosting. Participating in daily family life is as important as exposure to cultural events and activities. The host family should be prepared to focus on sharing their family life and cultural with the youth, and discouraged from seeing their role as a "tour guide" for the youth they are hosting. None of the interviewees spoke much about sites they saw while abroad, but they all spoke at length about the ways their host families shared their home, lives, and cultures.

Fourth, connect youth to additional opportunities post-exchange. A key element of all the life courses we traced in this study was the opportunities for additional travel, exchanges, and international educational opportunities. Several of the interviewees commented on the evolving and growing nature of their interest and experience in international affairs. One particular opportunity is providing youth with information about college majors that can have an international emphasis, as well as opportunities commonly found in college, such as study abroad and international service opportunities. Youth should also be encouraged to participate in an additional exchange, as doing so was a key step for many of the participants we interviewed.

Fifth, youth should be exposed to a variety of international career opportunities, which may or may not require living abroad. In today's global marketplace, many careers will have an international emphasis, as we saw in our study in the area of see production and jewelry.

Finally, youth should be encouraged to follow and expand their interest in other people, places, language and cultures. One of the key findings of this study is that each of the participants expressed interest in learning about other people and places. Youth with such interests lack the life experience to easily understand the opportunities that are available to them. Recognizing such interest and "fanning the flame" through exposure to new opportunities can be one of the most important links between participating in an international exchange as a youth and becoming a global citizen.

ACKNOWLEDGEMENTS: The lead author is grateful for the financial support from the States' 4-H International $(\mathrm{S} 4-\mathrm{H})$ program that provided the resources and time to conduct this research. 


\section{References}

Anderson, A. (2005). The community builder's approach to theory of change: A practical guide to theory and development. New York: The Aspen Institute Roundtable on Community Change.

Bachner, D.J., Zeutschel, U., \& Shannon, D. (1993). Methodological issues in researching the effects of U.S.-German educational youth exchange: A case study. International Journal of Intercultural Relations, 17(1) 41-71

Boyd, B.L., Giebler, C., Hince, M., Liu, Y., Mehta, N., Rash, R., Rowald, J., Saldana, C., \& Yanta, Y. (2001). Does study abroad make a difference? An impact assessment of the international 4-H youth exchange program. Journal of Extension, 39(5). Online:

http://www.joe.org/joe/20010ctober/rb8.php.

Creswell, J. (2003). Research design: Qualitative, quantitative, and mixed methods approaches ( $2^{\text {nd }}$ ed.). Thousand Oaks, CA: Sage.

Flick, U. (2007). Managing quality in qualitative research. Thousand Oaks, CA: Sage.

Hansel, B. (1988). Developing an international perspective in youth through exchange programs. Education \& Urban Society, 20, 177-195.

Olberding, J.C., \& Olberding, D.J. (2010). "Ripple effects" in youth peacebuilding and exchange programs: Measuring impacts beyond direct participants. International Studies Perspectives, 11(1), 75-91.

Strauss, A., \& Corbin, J. (1990). The basics of qualitative research: Grounded theory procedures and techniques ( $2^{\text {nd }}$ ed.). Thousand Oaks, CA: Sage.

U.S. Department of Education. (2012). Succeeding globally through international education and engagement. Author: Washington, DC.

(C) Copyright of Journal of Youth Development Bridging Research and Practice. Content may not be copied or emailed to multiple sites or posted to a listserv without copyright holder's express written permission. Contact Editor at: patricia.dawson@oregonstate.edu for details. However, users may print, download or email articles for individual use.

ISSN 2325-4009 (Print); ISSN 2325-4017 (Online) 
